\title{
Commercial golf glove effects on golf performance and forearm muscle activity
}

Graeme G. Sorbie, Paul Darroch, Fergal M. Grace, Yaodong Gu, Julien S. Baker and Ukadike C. Ugbolue

This is an Accepted Manuscript of an article published by

Taylor \& Francis in Research in Sports Medicine: an International Journal on 18th August 2017, available online: http://dx.doi.org/10.1080/15438627.2017.1365291 
1 Research in Sport Medicine - GSPM-2016-0149.R1

2 Accepted: $5^{\text {th }}$ April

\section{Commercial golf glove effects on golf performance 4 and forearm muscle activity}

$5 \quad{ }^{1,2}$ Graeme G. Sorbie; ${ }^{1}$ Paul Darroch; ${ }^{1,3}$ Fergal M. Grace; ${ }^{4}$ Yaodong Gu; ${ }^{1}$ Julien S. Baker and ${ }^{1,5}$ Ukadike

6 C. Ugbolue

7

$8{ }^{1}$ School of Science and Sport, Institute for Clinical Exercise \& Health Science, University of the West 9 of Scotland, Hamilton, ML3 OJB, United Kingdom;

${ }^{2}$ Division of Sport and Exercise Sciences, Abertay University, Dundee, DD1 1HG, United Kingdom

${ }^{3}$ Faculty of Faculty of Health, Human Movement and Sport Sciences, Federation University Australia, Ballarat, Victoria, Australia;

${ }^{4}$ Faculty of Sports Science, Ningbo University, China;

${ }^{5}$ Department of Biomedical Engineering, University of Strathclyde, Glasgow, United Kingdom

\section{Corresponding author}

Ukadike Chris Ugbolue

Biomechanics Laboratory

15 School of Science and Sport,

16 Institute for Clinical Exercise \& Health Science,

17 University of the West of Scotland,

18 Hamilton, ML3 OJB,

19 United Kingdom

Phone: +44 (0)1698 283100 Ext 8284

Email: u.ugbolue@uws.ac.uk;

\section{$\underline{\text { Abstract }}$}


1 Purpose To determine whether or not commercial golf gloves influence performance variables and

2 forearm muscle activity during golf play. Methods Fifteen golfers participated in the laboratory

3 based study, each performing 8 golf swings with a Driver and 7-iron whilst wearing a glove and 8

4 without wearing the glove. Club head speed, ball speed and absolute carry distance performance

5 variables were calculated. Surface electromyography was recorded from the flexor digitorum

6 superficialis and extensor carpi radialis brevis on both forearm muscles. Results Club head speed,

7 ball speed and absolute carry distance was significantly higher when using the Driver with the glove

8 in comparison to the Driver without the glove $(p<0.05)$. No significant differences were evident

9 when using the 7-iron and no significant differences were displayed in muscle activity in either of the

10 conditions. Conclusion Findings from this study suggest that driving performance is improved when

11 wearing a glove.

Keywords: Club Head Speed, Ball Speed, EMG, ECRB, FDS

14

15

Word Count: 4214 
1 Golf has become an increasingly popular sport for players of differing ages and skill levels (Farrally et

2 al., 2003). A golfer's prime objective is to finish a golf round using minimum shots. Several key

3

4

5

6

7

8

9 factors for improving golf performance have been previously identified; including improving physical characteristics through golf training programmes (Lephart, Smoliga, Myers, Sell, \& Tsai, 2007) and coaching to improve swing mechanics (Hume, Keogh, \& Reid, 2005). In addition, golfers will also change equipment in an attempt to improve performance, which is also common amongst other sports (Stefanyshyn \& Wannop, 2015).

Commercial golf gloves are not a required piece of equipment when playing golf but are often used by golfers to assist perceived level of performance. Leading manufacturers claim that the golf glove helps to create friction between the hand and golf grip when holding the club, thus potentially increasing the performance of the golfer. However, to our knowledge, there is no published research to support these performance enhancement claims. The friction created between the fingers/palm of the hand and different types of sports equipment can often influence how well the athletes are able to perform (Lewis et al., 2014). The friction generated not only controls how well different objects can be gripped, but also how the equipment feels to the athlete and what the perceived level of performance is (Lewis et al., 2014). For example, during wheelchair rugby the use of gloves is promoted to increase the friction between the hand and wheelchair. Lutgendorf et al. (2009) showed that the use of an NFL glove significantly increased acceleration and agility compared to various other gloves and therefore increased performance of the athlete. It was found that, acceleration and agility were also reduced when athletes did not wear a glove (bare hand).

A key component in improving golf performance is being able to increase the distance and accuracy of the golf shot within the long game. Fundamentals to this are club head speed (CHS), ball speed (BS) and club face angle at impact (Fradkin, Sherman, \& Finch, 2004). Egret et al. (2003) reported a CHS of $161 \mathrm{~km} / \mathrm{h}$ whilst using a Driver and Sorbie et al. (2016) reported CHS of $126 \mathrm{~km} / \mathrm{h}$ when using a 7-iron, thus clearly showing distinct differences between longer and shorter golf clubs. Due to 
these high levels of CHS, a significant force from the forearm is required in order to allow the golfer to maintain grip throughout the golf swing (Komi, Roberts, \& Rothberg, 2008).

Previous research has reported high levels of forearm muscle activity from the flexor and extensor muscles during the golf swing using the electromyography (EMG) technique. Farber et al. (2009) reported levels of up to $74 \%$ of maximum voluntary contraction (MVC) during the forward swing phase, and up to $128 \%$ of MVC during the acceleration phase when examining the extensor carpi radialis brevis (ECRB) muscle whilst using the golf Driver. Sorbie et al. (2016) reported somewhat lower levels of muscle activity from the flexor digitorum superficialis (FDS) (89.3\%) and ECRB (87.8\%) muscles of the forearm during the golf swing, however, these swings were performed using the 7iron.

Several industrial studies have used EMG to assess forearm muscle activity when using gloves (Kovacs, Splittstoesser, Maronitis, \& Marras, 2002; Larivière et al., 2004). Although these studies are not directly comparable to the golf swing, Larivière et al. (2004) reported changes in ECRB and FDS forearm muscle activation levels when performing handgrip tests with a glove compared to the bare hand (15\% increase on average). Kovacs et al. (2002) also reported an increase in EMG forearm muscle activation levels when comparing the bare hand grip to several different glove materials. A biomechanical assessment using EMG could provide important information on the loading of the forearm muscles during the golf swing when using the golf glove compared to using the bare hand. Specifically, a reduction on the load placed on the forearm muscles may help prevent injuries to the elbow area (Dickerson, Martin, \& Chaffin, 2007). Lateral and medial epicondylitis are two of the main elbow symptoms associated with golfers, especially golfers within the amateur category (Farber et al., 2009; Glazebrook, Curwin, Mohammad, Kozey, \& William, 1994).

When considering the previously reported performance and muscle activity changes when using gloves in industrial work and specific sporting events, it was reasonable to hypothesise that performance variables and muscle activity may change during the golf swing when wearing a glove 
compared to the bare hand. Furthermore, with the significant changes in CHS between the Driver and iron clubs, an assessment between these clubs is also required when using the commercial golf glove. Thus, the purpose of the present study was to determine how a commercial golf glove influences performance CHS, BS and Absolute Carry Distance (ACD) and forearm muscle activity during a golf swing whilst using the Driver and the 7-iron.

\section{$6 \quad$ Methods}

\section{Participants}

8 After obtaining ethical approval from the university ethics committee, fifteen right-handed male 9 golfers participated in this laboratory based study (height: $183.7 \pm 7.3 \mathrm{~cm}$, weight: $77.6 \pm 9.8 \mathrm{~kg}$, age: $24.3 \pm 4.0$ years, handicap: $18.0 \pm 5.6$, effect size $<0.5 ; \alpha$ err prob $=0.05$, Power $=80 \%)$. All participants were free from injury. Participants were also required to have no elbow or wrist injuries in the past year and no surgery in the identified areas in the past five years. The researchers explained the procedures and purpose of the study to all participants. All participants completed a physical readiness questionnaire and consent form prior to participation in the study.

\section{Apparatus}

The experimental set-up included: an artificial golf mat placed in the centre of the laboratory; an enclosed golf net (Sports Net Company, United Kingdom) located $2 \mathrm{~m}$ from the golf mat (Longridge, United Kingdom); an 8 camera Vicon Bonita (Oxford Metrics Ltd, United Kingdom) Motion Analysis System operating at $250 \mathrm{~Hz}$ positioned at strategic positions around the golfer; a set of 8 EMG Transmitters operating at $1000 \mathrm{~Hz}$ and filtered at 10-500 Hz (Myon 320, Schwarzenberg, Switzerland) in conjunction with Surface Electrodes (AMBU, Cambridgeshire, UK) used to measure muscle activity. A Digital Handheld Dynamometer (Medical research, Leeds, UK) was used to measure Maximal Voluntary Contractions (MVC). The EMG system was synchronised in conjunction with the Vicon Bonita Motion Analysis System to facilitate simultaneous data collection. The Voice Caddie 
1 Swing Launch Monitor SC 100 GPS (La Mirada, CA, USA) was used to calculate CHS, BS and ACD of each golf shot. The Launch Monitor was previously validated in-house against the Vicon Bonita Motion Analysis System; Trackman ${ }^{\mathrm{TM}}$ III Golf Swing and Ball Flight Analysis System (Brighton, MI, USA).

For the golf shots, a Taylormade (Basingstoke, UK) Speed Blade Stiff Shaft 7-iron, with a shaft length of 37 inches and a Taylormade SLDR Stiff Shaft Driver, with a shaft length of 45.5 inches were used. Titleist Pro-V1 (Titleist, Cambridgeshire, UK) golf balls were also used for all golf shots. Each of the clubs had 4 retro-reflective markers attached to them; this enabled the determination of the five phases of the golf swing using the Nexus 2 Vicon Data Capture Software. These markers were placed on the base of the grip, halfway down the club, the hosel of the club, and the club head (Higdon, Finch, Leib, \& Dugan, 2012). To enable the analysis of the golf swing, researchers often divide the golf swing into the five phases that are detailed in Figure 2 (Farber et al., 2009; Lim, Chow, \& Chae, 2012; Marta, Silva, Vaz, Bruno, \& Pezarat-correia, 2013; Marta, Silva, Vaz, Castro, \& Pezarat-correia, 2015; Sorbie et al., 2016). Taylormade ST (Taylormade, Basingstoke, UK) synthetic gloves were used as part of the experiment. Small, medium, medium/large, large, and extra-large groves were available to participants. The glove was required to fit comfortably across the palm and finger regions of the hand.

\section{Electromyography Procedure}

In order to reduce the impedance of the interface between the skin and electrode, the skin was prepared by removing hair from the forearm, alcohol cleaned and abraded for electrical connectivity. The electrodes were then placed on the ECRB and FDS forearm muscles on the left and right arms (Figure 1). To standardise the placement of the electrodes of the ECRB muscle a line was marked between the lateral epicondyle and the radial styloid process. The ECRB is located in the proximal half of the forearm, just lateral to the line (Basmajian, 1989). The electrode for the FDS 
1 muscle was placed towards the middle of the forearm, halfway from the ventral midline to the

2 medial border of the forearm (Blackwell, Kornatz, \& Heath, 1999).

3 Following the EMG electrodes being secured and the signals verified, participants performed two $3 \mathrm{~s}$

4 maximum isometric handgrip contractions in maximum flexion for the FDS reference. Participants then performed two $3 \mathrm{~s}$ maximum isometric handgrip contractions in maximum extension for the ECRB reference. Specifically, participants were instructed to slowly increase the force and be at maximum effort after 3-5s, and hold the maximum force for a further $3 \mathrm{~s}$. Participants were given 5 minutes recovery time between each contraction. During the contractions, the forearm was secured in a previously validated rig in order to minimize elbow and shoulder movement. The rig held the elbow at approximately $120^{\circ}$ during the handgrip recordings. The mean of $500 \mathrm{~ms}$ at the highest signal portion of the MVC was examined in order to normalize the golf swing (Konrad, 2006). The activity patterns of the golf swing were assessed every $20 \mathrm{~ms}$ and expressed as a percentage of MVC (Farber et al. 2009).

\section{Experimental Design}

Prior to collecting golf swing data, participants were asked to perform a dynamic warm-up routine targeting the full body. After the warm-up routine was complete the participants performed several golf shots. The testing process comprised:

- 8 shots with the Driver using the glove $(G)$

- 8 shots with the Driver without using the glove (NG)

- 8 shots with the 7-iron using the glove $(G)$

- 8 shots with the 7-iron without using the glove (NG)

All golf shots in the session were hit at a rate of one shot every $30 \mathrm{~s}$. During a pilot study, golfers stated that this was a comfortable pace to perform the golf shots. Between each of the conditions participants rested for 2 minutes to avoid muscular fatigue of the forearm. The participants were 
1 asked to aim towards a red target pole which was situated behind the golf net and advised to take

2 into consideration the accuracy and distance of their normal Driver and 7-iron shots. The order of

3 this process was randomised using a processing generator (TextFixer: www.testfixer.com). This

4 minimised any systematic error in testing. During each of the golf shots that were performed, video,

$5 \quad$ EMG and performance data was recorded.

6

7 For the performance variables and EMG data, mean values were calculated for 8 golf shots

\section{Data Analysis} performed by each participant during each of the 4 conditions. Following this, mean values were calculated across participants. Normal distribution for all variables was assessed using the ShapiroWilk test (McCormick et al. 2014). A null hypothesis for the tests was accepted due to all $p$ values being higher than 0.05 . Upon this being determined a two-way repeated measures ANOVA was used to identify differences in EMG data sets when using the golf glove compared to not using the golf glove (bare hand), during the five phases of the golf swing (Farber et al., 2009; Lim et al., 2012; Marta et al., 2013, 2015; Sorbie et al., 2016). Muscle activity was expressed as a percentage of the MVC. All performance variables were analysed for statistical significance using a paired t-test. Additionally, all calculations were performed on SPSS (version 22) and Microsoft Excel (version 2010), and $p<0.05$ was considered significant.

\section{$\underline{\text { Results }}$}

\section{Performance}

\section{Driver}

Participants displayed significantly higher CHS with the Driver $\mathrm{G}(150.76 \mathrm{~km} / \mathrm{h} \pm 7.63)$ in comparison to the Driver NG (146.93 km/h \pm 9.56$)(p=0.025)$ (Figure 3). Participants displayed significantly higher BS with the Driver $\mathrm{G}(218.57 \mathrm{~km} / \mathrm{h} \pm 15.39)$ in comparison to the Driver NG $(212.49 \mathrm{~km} / \mathrm{h} \pm$ 
1 16.21) ( $p=0.030)$ (Figure 4). The ACD was also significantly increased when comparing the Driver $\mathrm{G}$

2 (204.41 $\mathrm{M} \pm 28.83)$ to the Driver NG (193.50 M \pm 27.28$)(p=0.012)$.

\section{7-iron}

4 Participants displayed no significant differences in CHS whilst using the 7 Iron G $(130.83 \mathrm{~km} / \mathrm{h} \pm 9.74)$

5 in comparison to the 7-iron NG $(128.25 \mathrm{~km} / \mathrm{h} \pm 9.31)(p=0.151)$ (Figure 3). No significant differences

6 were displayed in BS when comparing the 7-iron $\mathrm{G}(167.07 \mathrm{~km} / \mathrm{h} \pm 17.14)$ to the 7-iron NG (162.58

$7 \mathrm{~km} / \mathrm{h} \pm 18.44)(p=0.068)$ (Figure 4). No significant differences were displayed between the ACD when comparing the 7-iron $\mathrm{G}(127.90 \mathrm{~m} \pm 18.88)$ to the 7-iron NG $(122.83 \mathrm{~m} \pm 18.30)(p=0.059)$.

\section{Muscle Activity}

\section{Comparison between Conditions (Glove vs No Glove)}

11 All participants displayed a similar trend in forearm muscle activity pattern when comparing the use of the glove and the bare hand whilst using the Driver and 7-iron. The muscle activity for the FDS and ECRB in the lead (left hand for right handed golfers) and trail (right hand for right handed golfers) arm for the five phases of the golf swing are displayed on Table 1. No significant differences were displayed in the FDS and ECRB muscle activity in the lead or trail arms during the five phases of the golf swing when comparing the use of the commercial golf glove and the bare hand (all $p>0.05$ ).

\section{Comparison between Phases}

The FDS and ECRB forearm muscles on the lead and trail sides displayed peak activation values during the forward swing, acceleration and early follow-through phases (Table 1). All muscles showed significant statistical differences between the peak activation (forward swing, acceleration and early follow-through) phases compared to the lower activation phases (backswing and late follow-through) (all $p<0.05)$. 
2 The aim of the present study was to determine how a commercial golf glove influences CHS, BS and

3 ACD when performing golf shots with the Driver and 7-iron. Secondly, the study aimed to investigate

4 the muscle activation levels from the forearm muscles when using the golf glove compared to the

5 bare hand whilst using the Driver and the 7-iron at the five phases of the golf swing.

6 The present study is in agreement with previously published research where performance in sports has been shown to improve with the use of a glove (Lewis et al., 2014; Lutgendorf et al., 2009). With similar results to the present study, where the researchers displayed a significant increase in CHS and BS, Lutgendorf et al. (2009) showed that the use of a glove in wheelchair rugby significantly increased acceleration compared to the bare hand. In addition to this, during ultimate frisbee, Lewis et al. (2014) reported that using a glove when catching the frisbee increased friction and, therefore, increased performance during the execution of the skill. The results of the present study also support the claim made by leading golf manufacturers that the commercial golf glove increases friction between the hand and the golf grip and, therefore, could have a positive impact on golf swing performance (Golfsmith, 2016). However, the result of the present study only displays this change to be significant when using the Driver and not the 7-iron. It could be suggested that the contrasting results between the Driver and 7-iron could be due to the Driver generating a significantly higher CHS when compared to the 7-iron $(p<0.05)$. These changes may also be a result of the forearm muscles generating marginally higher activation levels when using the Driver compared to the 7-iron, which supports previously published literature (Farber et al., 2009; Glazebrook et al., 1994; Sorbie et al., 2016). The contrasting results could also be due to the Driver having a longer shaft length compared to the 7-iron and the two clubs being used for different shots in the golf game. The Driver is used to hit the ball as far as possible (Nagao \& Sawada, 1973), whereas the 7-iron club is mainly used for shots between $100 m-150 m$ where high accuracy and precision is essential (Egret et al., 2003). 
1 With regards to forearm muscle activity, the present study is somewhat contrasting to other

2 published research. Larivière et al. (2004) and Kovacs et al. (2002) reported an increase in forearm

3 muscle activation levels during a handgrip test when wearing a glove compared to the bare hand. In contrast, the present study shows that there is no significant change in forearm muscle activity when wearing the golf glove compared to not wearing the golf glove whilst using the Driver or 7-iron. These contrasting findings may be a result of the high variability of the muscle activation levels or due to the static components of the handgrip test and the dynamic movement of the golf swing. With no increased load placed on the forearm muscles when comparing the commercial golf glove to the bare hand during the golf swing, it could be suggested that using the golf glove does not reduce the risk of injury to the elbow (Dickerson et al., 2007). Previous studies have shown that increased forearm muscle activity may increase the risk of medial and lateral epicondylitis when performing the golf swing (Farber et al., 2009; Glazebrook et al., 1994).

With reference to the five phases of the golf swing, the present study displays distinct differences in forearm muscle activation between the five phases. The results from the present study show that in most cases the lead and trail forearm muscles are more active during the forward swing, acceleration and early follow-through phases compared to the backswing and late follow-through phases. These finding are in agreement with Farber et al. (2009) and Sorbie et al. (2016) where these researchers displayed a similar trend when examining forearm muscle activity when using the Driver and 7-iron clubs respectively. Specifically, Farber et al. (2009) showed that the ECRB muscle on the lead arm increased progressively between the backswing (21.3\% EMG), forward swing (74.2\% MVC) and acceleration (94.2\% EMG) phases when examining amateur golfers. Additionally, muscle activity then progressively reduced between the acceleration (94.2\% EMG), early follow-through (32.1\% EMG) and late follow-through (31.1\% EMG) phases of the golf swing. With regards to the muscle activation values of the ECRB muscle, Farber et al. (2009) displayed higher values during the forward swing, acceleration and late follow-through phases compared to the current study. These changes may be a result of the higher mean handicap (18.0 mean handicap) in the current study compared 
1 the study by Farber et al. (2009) (15.1 mean handicap). However, these changes may also be a result

2 of different methodologies used between the two studies. Farber et al. (2009) used fine-wire EMG to collect muscle activity from the forearm muscles whereas the present study used surface EMG.

The researchers acknowledge that there are some limitations to the present study. Firstly, it must be considered that EMG signal crosstalk from surrounding extensor and flexor muscles is a limitation to the current study. The following steps were taken to reduce EMG signal cross-talk between muscles. The surface electrodes were positioned within the middle of the muscle belly of the FDS and ECRB forearm muscles and applied in parallel arrangement to the muscle fibres, with a centre to centre inter-electrode distance of $2 \mathrm{~cm}$. Secondly, this study only investigated one commercial golf glove material. Future studies in this area could investigate the difference between using the leather and the hybrid gloves. Thirdly, all participants in the present study used an interlock gripping style, further research should be performed to investigate if different gripping styles have the same significant effect between wearing a golf glove and not wearing a golf glove when using the Driver. Finally, testing was limited to an indoor laboratory facility therefore ACD was calculated from the CHS, BS and launch angle. Further investigation is also required to identify the point between the Driver and 7-iron where the three performance variables tested are not significantly increased.

\section{Conclusion}

To summarise, the results of this study showed a significant increase in CHS, BS and ACD whilst using a Driver with the glove compared to using a Driver without the glove, however, no significant differences were evident when using the 7-iron. Muscle activity in the forearm did not change whilst using the Driver or 7-iron in either of the variables that were tested, therefore, it is unlikely that the commercial golf glove has any effect on elbow injuries within amateur golfers. The data from this study suggest that golfers could increase their long game performance by wearing a glove if they choose to use it whilst using the Driver.

\section{Reference}


Basmajian, J. (1989). Biofeedback; principles and practice for clinicians. Wiliams \& Wilkins, Baltimore.

Blackwell, J. R., Kornatz, K. W., \& Heath, E. M. (1999). Effect of grip span on maximal grip force and fatigue of flexor digitorum superficialis. Applied Ergonomics, 30(5), 401-405. http://doi.org/10.1016/S0003-6870(98)00055-6

Dickerson, C. R., Martin, B. J., \& Chaffin, D. B. (2007). Predictors of perceived effort in the shoulder during load transfer tasks. Ergonomics, 50(7), 1004-1016. http://doi.org/10.1080/00140130701295947

Egret, C. I., Vincent, O., Weber, J., Dujardin, F. H., \& Chollet, D. (2003). Analysis of 3D kinematics concerning three different clubs in golf swing. International Journal of Sports Medicine, 24(6), 465-470. http://doi.org/10.1055/s-2003-41175

Farber, A. J., Smith, J. S., Kvitne, R. S., Mohr, K. J., \& Shin, S. S. (2009). Electromyographic analysis of forearm muscles in professional and amateur golfers. The American Journal of Sports Medicine, 37(2), 396-401. http://doi.org/10.1177/0363546508325154

Farrally, M. R., Cochran, A. J., Crews, D. J., Hurdzan, M. J., Price, R. J., Snow, J. T., \& Thomas, P. R. (2003). Golf science research at the beginning of the twenty-first century. Journal of Sports Sciences, 21, 753-765. http://doi.org/10.1080/0264041031000102123

Fradkin, A., Sherman, C., \& Finch, C. (2004). How well does club head speed correlate with golf handicaps? Journal of Science and Medicine in Sport, 7(4), 465-472. http://doi.org/10.1016/S1440-2440(04)80265-2

Glazebrook, M. A., Curwin, S., Mohammad, N., Kozey, J., \& William, D. (1994). Medial epicondylitis. The American Journal of Sports Medicine, 22(5), 674-679.

Golfsmith. (2016). GolfSmith - Golf Glove.

Higdon, N. R., Finch, W. H., Leib, D., \& Dugan, E. L. (2012). Effects of fatigue on golf performance. Sports Biomechanics, 11(2), 190-196. http://doi.org/10.1080/14763141.2011.638386

Hume, P. A., Keogh, J., \& Reid, D. (2005). The role of biomechanics in maximising distance and accuracy of golf shots. Sports Medicine, 35(5), 429-449.

Komi, E. R., Roberts, R. J., \& Rothberg, S. J. (2008). Measurement and analysis of grip force during a golf shot. Journal of Sports Engineering and Technology, 221(1), 23-35.

Konrad, P. (2006). A practical introduction to kinesiological electromyography. N. INC, The ABC of EMG, USA, 1-61.

Kovacs, K., Splittstoesser, R., Maronitis, A., \& Marras, W. S. (2002). Grip force and muscle activity differences due to glove type. AlHA Journal, 63(3), 269-74. http://doi.org/10.1080/15428110208984713

Larivière, C., Plamondon, A., Lara, J., Tellier, C., Boutin, J., \& Dagenais, A. (2004). Biomechanical assessment of gloves. A study of the sensitivity and reliability of electromyographic parameters used to measure the activation and fatigue of different forearm muscles. International Journal of Industrial Ergonomics, 34(2), 101-116. http://doi.org/10.1016/j.ergon.2004.02.002 
Lephart, S., Smoliga, J., Myers, J., Sell, T., \& Tsai, Y. (2007). An eight-week golf-stretching exercise program improves physical characteristics, swing mechanics, and golf performance in recreational golfers. Journal of Strength and Conditioning Research, 21(3), 860-869. http://doi.org/10.1519/R-20606.1

Lewis, R., Carré, M. J., \& Tomlinson, S. E. (2014). Skin friction at the interface between hands and sports equipment. Procedia Engineering, 72(0), 611-617. http://doi.org/10.1016/j.proeng.2014.06.064

Lim, Y.-T., Chow, J. W., \& Chae, W.-S. (2012). Lumbar spinal loads and muscle activity during a golf swing. Sports Biomechanics, 11(2), 197-211. http://doi.org/10.1080/14763141.2012.670662

Lutgendorf, M., Mason, B., Woude, L. Van Der, Louise, V., Tolfrey, G., Lutgendorf, M., ... Louise, V. (2009). Effect of glove type on wheelchair rugby sports performance. Sports Technology, 2(3), 121-128. http://doi.org/10.1080/19346182.2009.9648509

Marta, S., Silva, L., Vaz, J., Bruno, P., \& Pezarat-correia, P. (2013). Electromyographic analysis of trunk muscles during the golf swing performed with two different llubs. International Journal of Sports Science \& Coaching, 8(4), 779-787.

Marta, S., Silva, L., Vaz, J. R., Castro, M. A., \& Pezarat-correia, P. (2015). Electromyographic analysis of lower limb muscles during the golf swing performed with three different clubs. Journal of Sports Sciences, 38(8), 713-720. http://doi.org/10.1080/02640414.2015.1069376

Nagao, N., \& Sawada, Y. (1973). A kinematic analysis in golf swing concerning driver shot and No. 9 iron shot. The Journal of Sports Medicine and Physical Fitness, 13, 4-16.

Sorbie, G. G., Hunter, H. S., Fergal, F. M., Gu, Y., Baker, J. S., \& Ugbolue, U. C. (2016). An electromyographic study of the effect of hand grip sizes on forearm muscle activity and golf performance. Research in Sports Medicine, 24(3), 207-218.

Stefanyshyn, D. J., \& Wannop, J. W. (2015). Biomechanics research and sport equipment development. Sports Engineering, 18(4), 191-202. http://doi.org/10.1007/s12283-015-0183-5 
Table 1: Mean and SD values for each muscle tested with and without the golf glove, in percentages of MVC

\begin{tabular}{|c|c|c|c|c|c|c|c|c|}
\hline Method & $\begin{array}{l}\text { FDS Lead } \\
\text { Arm }\end{array}$ & $\begin{array}{c}\text { ECRB Lead } \\
\text { Arm }\end{array}$ & $\begin{array}{l}\text { FDS Trail } \\
\text { Arm }\end{array}$ & $\begin{array}{c}\text { ECRB Trail } \\
\text { Arm }\end{array}$ & $\begin{array}{l}\text { FDS Lead } \\
\text { Arm }\end{array}$ & $\begin{array}{c}\text { ECRB Lead } \\
\text { Arm }\end{array}$ & $\begin{array}{c}\text { FDS Trail } \\
\text { Arm }\end{array}$ & $\begin{array}{l}\text { ECRB Trail } \\
\text { Arm }\end{array}$ \\
\hline Glove & (Driver G) & & & & (7-iron G) & & & \\
\hline Backswing & $46.45 \pm 18.89$ & $36.78 \pm 14.08$ & $24.19 \pm 8.20$ & $46.54 \pm 17.20$ & $41.77 \pm 17.41$ & $35.83 \pm 11.76$ & $24.27 \pm 7.98$ & $47.83 \pm 19.64$ \\
\hline Forward swing & $63.22 \pm 24.80$ & $44.54 \pm 20.47$ & $65.27 \pm 19.49$ & $59.42 \pm 20.73$ & $51.35 \pm 19.54$ & $44.79 \pm 14.49$ & $68.52 \pm 24.46$ & $54.04 \pm 19.83$ \\
\hline Acceleration & $56.76 \pm 20.41$ & $69.61 \pm 20.15$ & $108.99 \pm 30.36$ & $55.35 \pm 19.77$ & $55.32 \pm 17.42$ & $76.49 \pm 21.22$ & $95.92 \pm 17.68$ & $55.64 \pm 14.16$ \\
\hline Early follow-through & $46.46 \pm 17.32$ & $60.90 \pm 23.31$ & $80.06 \pm 20.31$ & $53.73 \pm 22.68$ & $45.55 \pm 15.41$ & $66.86 \pm 20.68$ & $67.26 \pm 20.74$ & $50.69 \pm 18.50$ \\
\hline Late follow-through & $38.21 \pm 17.74$ & $35.40 \pm 14.57$ & $44.35 \pm 21.35$ & $35.55 \pm 14.00$ & $37.71 \pm 19.15$ & $32.49 \pm 17.02$ & $39.90 \pm 17.53$ & $33.08 \pm 11.58$ \\
\hline No Glove & (Driver NG) & & & & (7-iron NG) & & & \\
\hline Backswing & $49.37 \pm 19.49$ & $37.33 \pm 13.67$ & $26.83 \pm 9.93$ & $45.13 \pm 16.37$ & $42.00 \pm 16.67$ & $38.38 \pm 14.29$ & $26.01 \pm 7.64$ & $48.22 \pm 19.32$ \\
\hline Forward swing & $55.95 \pm 20.32$ & $48.49 \pm 20.81$ & $67.29 \pm 18.08$ & $56.68 \pm 17.86$ & $55.09 \pm 23.24$ & $46.63 \pm 14.78$ & $72.39 \pm 20.40$ & $56.24 \pm 19.83$ \\
\hline Acceleration & $62.28 \pm 20.25$ & $66.69 \pm 27.15$ & $110.24 \pm 21.74$ & $62.94 \pm 22.48$ & $59.01 \pm 19.92$ & $78.62 \pm 20.34$ & $94.61 \pm 18.80$ & $57.36 \pm 20.16$ \\
\hline Early follow-through & $47.10 \pm 16.52$ & $63.90 \pm 23.41$ & $85.63 \pm 21.60$ & $55.53 \pm 21.51$ & $46.84 \pm 13.92$ & $68.03 \pm 20.68$ & $68.67 \pm 17.93$ & $49.54 \pm 13.73$ \\
\hline Late follow-through & $35.69 \pm 15.23$ & $35.45 \pm 15.72$ & $45.30 \pm 23.87$ & $40.46 \pm 14.76$ & $39.55 \pm 18.60$ & $32.77 \pm 17.01$ & $41.46 \pm 15.62$ & $34.70 \pm 12.14$ \\
\hline
\end{tabular}




\section{$\underline{\text { Tables and Figures }}$}

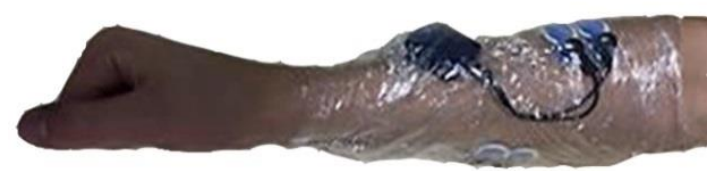

Figure 1: Electrodes placed on the FDS and ECRB forearm muscles with transmitters secured to the forearm using Plastic Wrap Cling Film (UK) (Image from Participant 6). 


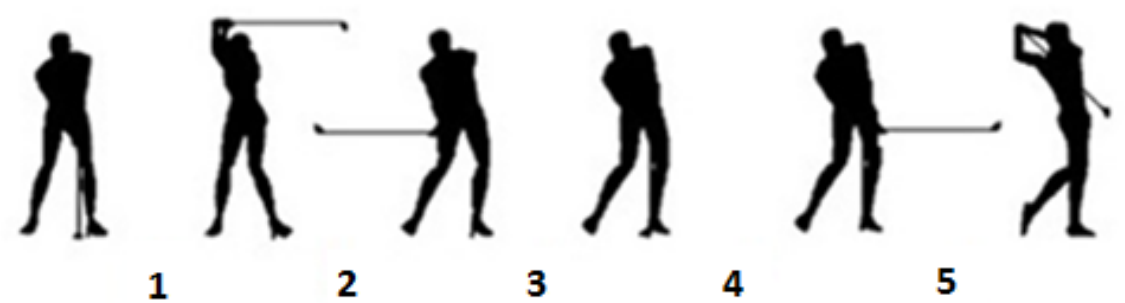

1

3

4

5

1. Backswing - From the ball address to the end of the backswing.

2. Forward Swing - From the end of the backswing until the club is horizontal to the ground on the golfer's trail side.

3. Acceleration - From the club being horizontal to the ground to the point of impact with the ball.

4. Early follow-through - From ball contact to the club being horizontal to the golfer's lead side.

5. Late follow-through - From the horizontal club position to the end of the motion.

Figure 2: Silhouette description of the phases of the golf swing (Farber et al., 2009). 


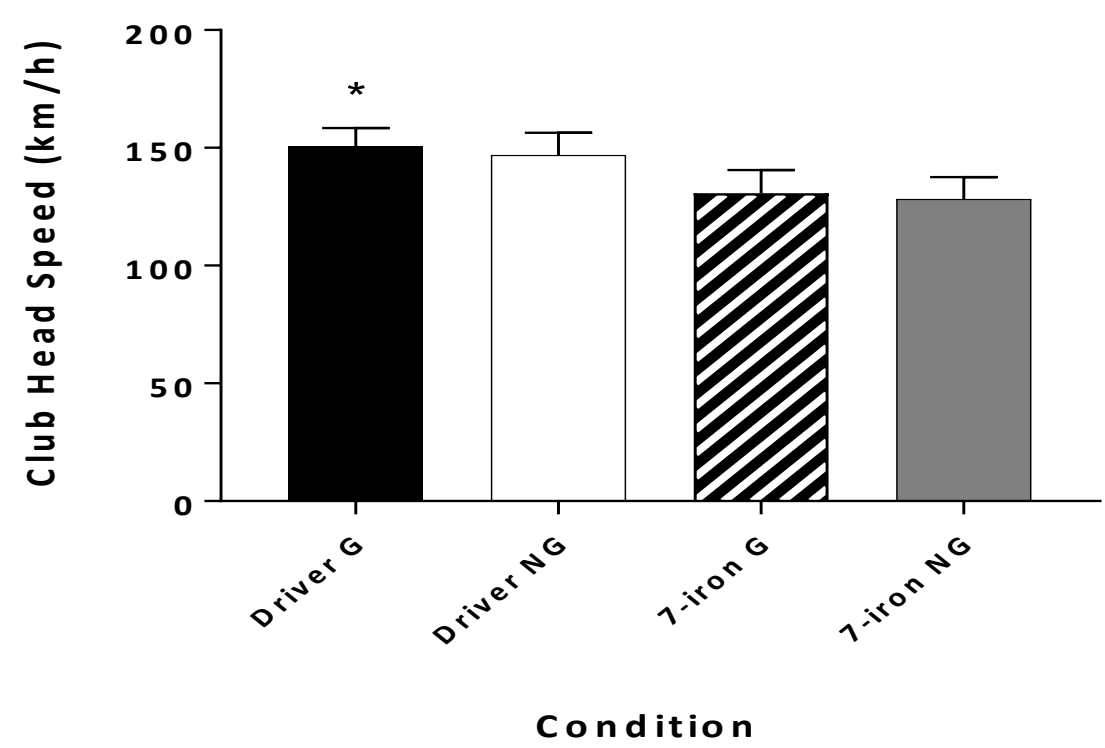

Figure 3: Driver G, Driver NG and 7-iron G, 7-iron NG - Club head speed *Significance between Driver $\mathrm{G}$ and Driver NG. 


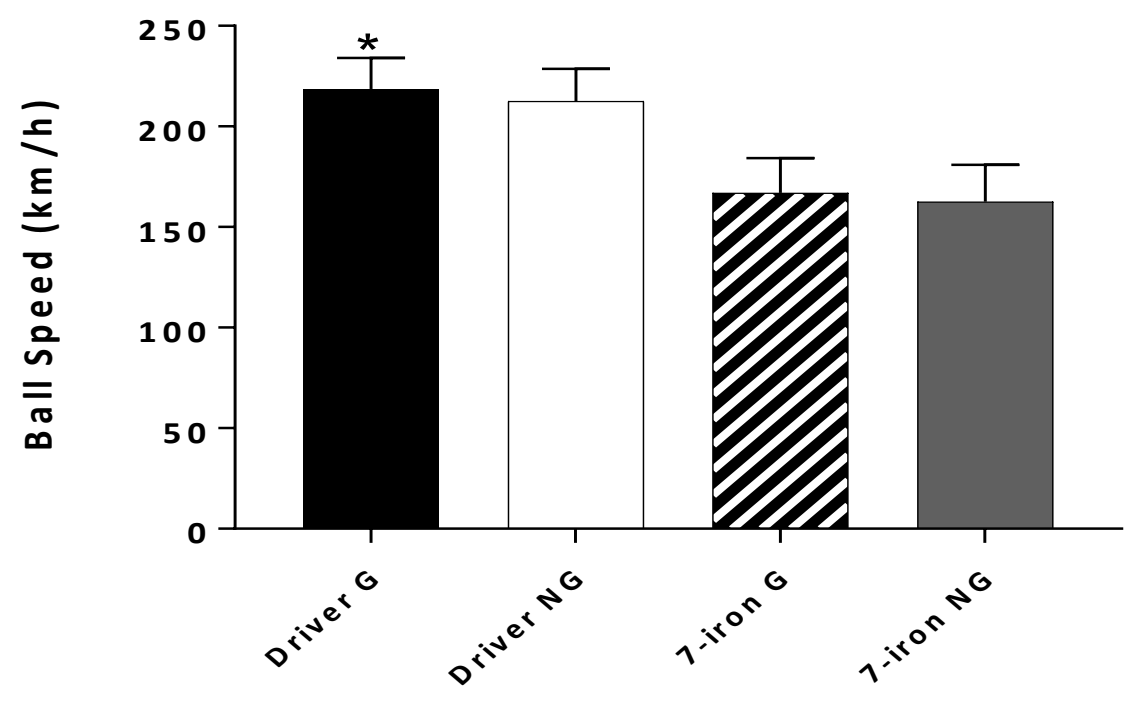

\section{Condition}

Figure 4: Driver G, Driver NG and 7-iron G, 7-iron NG - Ball Speed *Significance between Driver G and Driver NG. 